\title{
MAXILLARY FRENECTOMY USING DIODE LASER: A CASE REPORT
}

\author{
N. Sukumar Singh ${ }^{1}$, N. Satish Kumar Singh², Pinky Thangjam ${ }^{3}$
}

\section{HOW TO CITE THIS ARTICLE:}

N. Sukumar Singh, N. Satish Kumar Singh, Pinky Thangjam. "Maxillary Frenectomy using Diode Laser: A case report". Journal of Evolution of Medical and Dental Sciences 2014; Vol. 3, Issue 29, July 21; Page: 8142-8146, DOI: $10.14260 /$ jemds/2014/3024

INTRODUCTION: Aesthetic concerns have led to an increasing importance in seeking dental treatment, with the purpose of achieving perfect smile. The continuing presence of a diastema between the maxillary central incisors in adults has often been considered as an aesthetic problem. The presence of an aberrant frenum being one of the etiological factors for the persistence of a midline diastema, the focus on the frenum has become essential. ${ }^{1}$

The frena may also jeopardize the gingival health by causing a gingival recession when they are attached too closely to the gingival margin, either because of an interference with the improper placement of a toothbrush or through the opening of the gingival crevice because of a muscle pull. ${ }^{2}$

Frenum consists of mucosal folds in the labial, buccal, and occasionally the lingual surface of the alveolar ridge, they act as flexible barrier limiting the movement of the lips, cheeks and sometimes the tongue. ${ }^{3}$ The proceedings of the World Workshop in Clinical Periodontics have outlined the rationale for the use of frenectomy. ${ }^{4}$

It should be considered in areas where there are restrictive problems associated with lip and tongue movement, closure of midline diastema due to orthodontic treatment ${ }^{5}$, purely aesthetic problems, and attachments in edentulous ridges compromising prosthesis, pulling gingiva lead to inflammation and pocket formation and tongue tie leading to speech problem. ${ }^{1}$

Until recently the classical or conventional frenectomy (surgically by scalpel and suturing) was the only way to remove the aberrant frenum. Modern technology now offers an alternative mode of treatment, like laser surgery. ${ }^{6}$

The word laser is an acronym for Light Amplification by Stimulated Emission of Radiation. The hypothetical origins and conceptual basis of a laser were initiated by Einstein in 19177. When laser light incident on a tissue surface, it can be reflected, scattered, absorbed or transmitted ${ }^{8}$. There are different types of lasers according to their different wavelengths and their interaction with tissues. They can be used for hard and soft tissues in oral cavity.

In soft tissue procedures (gingivectomy, frenectomy, lesion removal) CO2, Nd: YAG, Argon, Er: YAG and Diode laser were used.9, 10 Diode laser is a semi-conductor (Gallium Aluminum Arsenide (GA Al As) used in surgery. It emits coherent monochromatic light of wavelength between (810-900) nanometer i.e. near infrared. This radiation is absorbed in dark media, as in hemoglobin and therefore has a remarkable surgical cutting efficiency in well vascularized tissues. ${ }^{11,12}$ This paper showcase a case presentation for maxillary frenectomy and removal of soft tissue overlying impacted canine using AMD laser Diode.

CASE SUMMARY: A female patient of age 21yrs came with the complains of midline spacing and wanted it to be closed. On intra oral examination, right maxillary canine was found missing and midline diastema with high frenum attachment can be seen (figure 1). On radiograph, right maxillary canine was impacted buccally. Patient had no other relevant medical history. She was informed of the 
problem rather than the midline spacing and agreed to undergo orthodontic treatment as well for retraction of the maxillary canine.

We also explained to the patient that only frenectomy could help her in closing the gap between the incisors. We explained the surgical procedure to the patient in detail and gave her the option to pick between the conventional surgical procedures or to do the same with using a dental laser.

On understanding the advantages of using the dental laser in her treatment plan, she readily accepted to go forward with dental diode laser treatment for both maxillary frenectomy and exposure of impacted canine.

The patient was not prescribed any medication before the procedure. Before starting the procedure, the patient was provided necessary protective covering and injected with infiltration anesthesia of $2 \%$ xylocaine preparation (Lignox $2 \%$ A, Indoco).

The laser diode that was used for the case had a wavelength of $810 \mathrm{~nm}$. The power used is of $1 \mathrm{~W}$ and in a pulsed mode.

During the procedure, minimal bleeding can be seen and hence were able to work in a very clear field. Also the patient experienced no discomfort during the procedure and took around 5 minutes in maxillary frenectomy (figure 2, 3). No sutures were placed and advised the patient to take analgesic whenever needed (Zerodol-P, IPCA) and recalled after 24hrs for post-operative observation.

On recalled visit, patient complained of mild pain and took a single dose of analgesic (ZerodolP, IPCA). On examination, initial epithelialization can be seen and patient had no post-operative bleeding in the first 24 hours.

The wound was clean and showed no signs of infection or inflammation. The patient was asked to then come for a follow up appointment after a week from the surgery. The healing was almost complete after one week of procedure. Patient showed no signs of discomfort and started the bracket bonding process for orthodontic treatment.

Patient was recalled for orthodontic appointment and check the progress. After 8 months of orthodontic treatment, complete closure of the midline spacing is complete and also the maxillary canine had been erupted in its desired position. A slide gingival inflammation was seen between lateral incisor and canine of maxillary right side and appropriate treatment was done for it.

Patient was happy with the result and the painless surgical procedure with the help of dental diode laser.

DISCUSSION: Photo thermal interaction with the tissue is the basis of surgical laser. In this process radiant light is absorbed by the tissue and transformed to heat energy changing tissue structure ${ }^{13}$. The amount of radiant light absorbed by oral tissues depend on a number of factors such as wavelength of laser radiation, output power at the laser tip, optical properties and composition of the target tissue. ${ }^{11}$

For the treated cases we used energy of 1.83J/second that gave best dry field (no bleeding) with good cutting efficiency and decreased postoperative complications. While bleeding in conventional method (scalpel) obscure the operative field and increases the fear of surgery especially in children and patients with bleeding disorders. As a result of the ability to perform the treatment without inflicting pain, it is an essentially stress free procedure for both the patient and the clinician. 
There was no postoperative pain the patient did not require a prescription for analgesic, unlike conventional way (surgically by scalpel, BP knife and suturing) where there is postoperative pain duo to damaging effect of scalpel, suturing, edema and swelling. There was no need to place sutures or pack, this decreased the need for postoperative visits. These results were similar to the findings of pick. ${ }^{10}$

CONCLUSION: In conclusion, it can be stated that use of diode laser showed promise as an alternative to conventional surgical procedure of scalpel (surgically by scalpel and suturing) and BP blade in all dental soft tissue surgical procedures like frenectomy and soft tissue removal for exposing impacted tooth. It has clinical relevance and sound biologic rationale that offers significant benefits to the patient and to the Dentist.

Like any new technology, lasers in dentistry also have a learning curve which, once mastered, is sure to enhance the clinician's skills

\section{BIBLIOGRAPHY:}

1. Huang WJ, Creath CJ. The midline diastema: a review on its etiology and treatment. Pediatric Dentistry 1995; 17: 171-9.

2. Jhaveri H. The Aberrant Frenum. In: Dr. Hiral Jhaveri (ed), Dr. PD Miller the father of periodontal plastic surgery, 2006; 29-34.

3. Daniel W. Soft Tissue Surgery. Lee F. Text Book of Practical Oral Surgery. Philadelphia, 1972: (1) 192-197.

4. Proceeding of workshop on Clinical Periodontics.V11 - 19.July 1989, Princeton, New Jersey.

5. Grabber T M. Orthodontics principles and practice. W. B. Saunders Co., 1966 p. 352.

6. Epstein S R, Stuart R. The frenectomy: Comparison of classic versus laser technique. Practical Periodontic and Aesthetic Dentistry1991. 3(5): 27-30.

7. Catone G A, Alling C C. Laser application in Oral and Maxillofacial Surgery. 1997. W. B. Saunders Company, Philadelphia.

8. Dederich D N. Laser tissue interaction. JADA1993; 124 (2) 57-61.

9. Weesner B W. Laser in Dentistry (Hand out for American Association for Dental Research). 1998.

10. Pick RM, Colvard MD. Current status of laser in soft tissue dental surgery. J Periodontol 1993; Jul; 64 (7): 589-602.

11. Fisher JC. Qualitative and Quantitative tissue effects from important surgical laser. Laser Surg Gyn 1993; (1) 58-81.

12. Gontijo I, Navarro RS, Hypek P, Ciamponi A, Land Hadded AE. The application of diode laser and Er: YAG laser in labial frenectomy in infant patients. J Dent Child (Chic) 2005; 72 (1):10-5.

13. Carruth J A, McKenzie A L. The production of Surgical laser lesions. Science and Clinical Practice 1985; I: 51-80. 


\section{CASE REPORT}

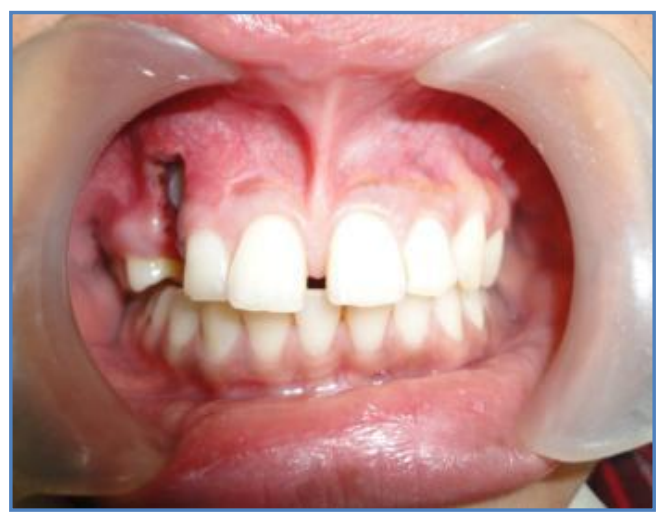

Fig. 1: Pre-operative view

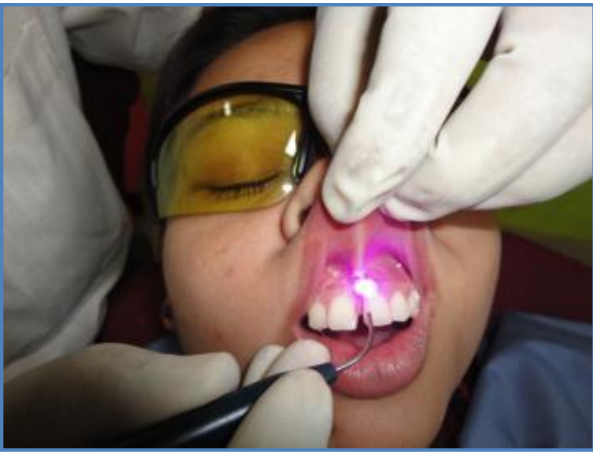

Fig. 3: Frenectomy of maxillary labial frenum using diode laser

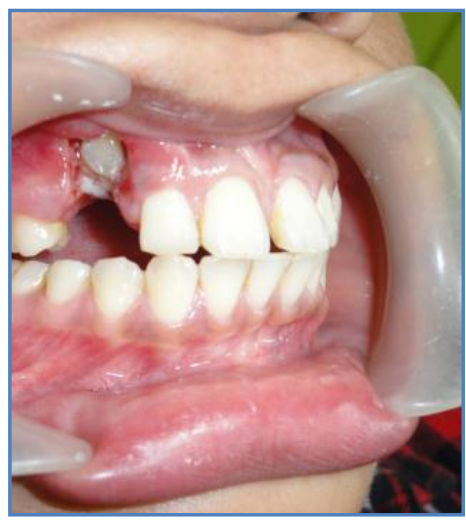

Fig. 2: Exposure of buccally impacted maxillary canine using diode laser

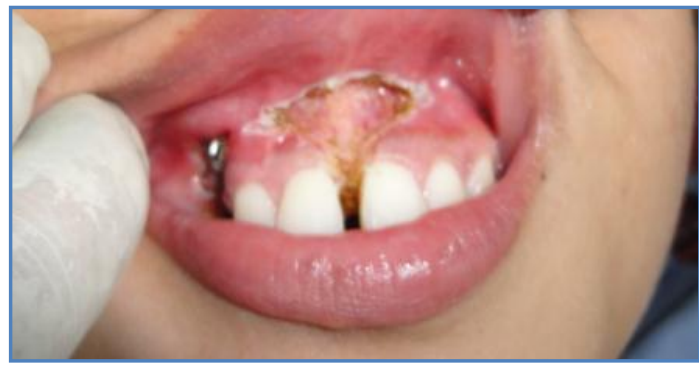

Fig. 4: After frenectomy using diode laser, no or minimal bleeding can be seen with clean and clear field
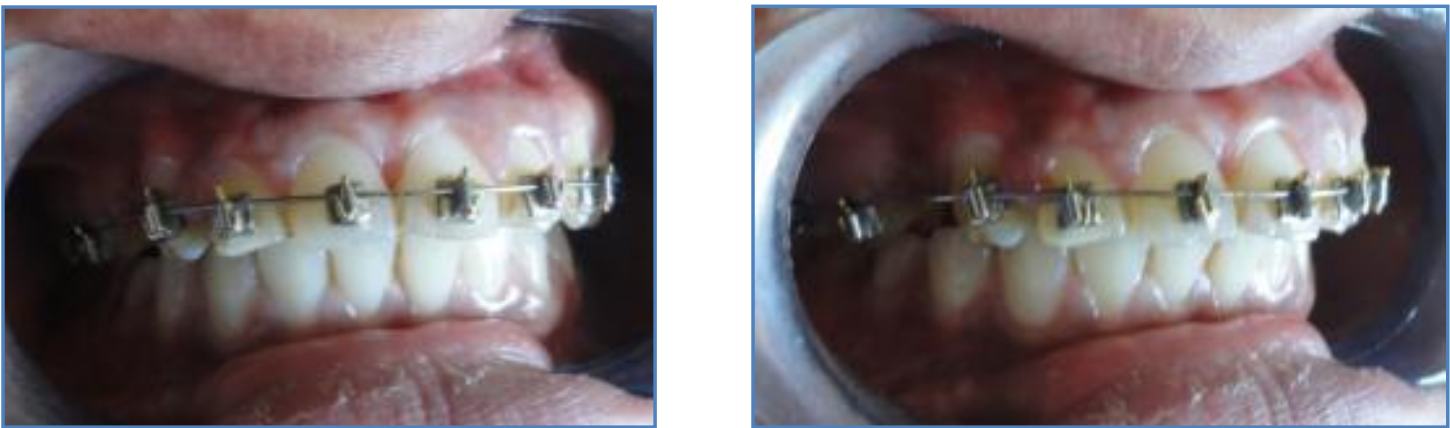

Fig. 5, 6: After 8 month of orthodontic procedure 


\section{CASE REPORT}

\section{AUTHORS:}

1. N. Sukumar Singh

2. N. Satish Kumar Singh

3. Pinky Thangjam

\section{PARTICULARS OF CONTRIBUTORS:}

1. Assistant Professor, Department of Dentistry, Jawaharlal Nehru Institute of Medical Sciences, Porompat, Imphal.

2. Assistant Professor, Department of Dentistry, Jawaharlal Nehru Institute of Medical Sciences, Porompat, Imphal.

3. Dental Surgeon, Department of Dentistry, Jawaharlal Nehru Institute of Medical Sciences, Porompat, Imphal.

\section{NAME ADDRESS EMAIL ID OF THE} CORRESPONDING AUTHOR:

Dr. N. Satish Kumar Singh,

Nagamapal Singjubung Leirak, Imphal-West-795001.

Email: drnsatish@gmail.com

Date of Submission: 28/06/2014.

Date of Peer Review: 29/06/2014.

Date of Acceptance: 10/07/2014.

Date of Publishing: 18/07/2014. 